\title{
Endobronchial Lesions from Disseminated Mycobacterium avium Infection in a Patient with Anti-interferon-gamma Autoantibodies
}

\author{
Yasutaka Mochizuka ${ }^{1}$, Masato Kono ${ }^{1}$, Ryutaro Hirama ${ }^{1}$, Yuiko Ohshima ${ }^{1}$, Kenichiro Takeda ${ }^{1}$, \\ Akari Tsutsumi ${ }^{1}$, Hideki Miwa ${ }^{1}$, Yoshihiro Miki ${ }^{1}$, Dai Hashimoto ${ }^{1}$, Toshiki Kimura ${ }^{2}$, \\ Takuro Sakagami ${ }^{2}$ and Hidenori Nakamura ${ }^{1}$
}

\begin{abstract}
:
A 78-year-old man was admitted to our hospital with a fever and left chest pain. Computed tomography showed multiple lung nodules, narrowing of the right bronchus intermedius with mediastinal lymphadenopathy, and an osteolytic lesion. Bronchoscopic findings showed rapid progression of multiple polypoid lesions and the bronchial stenosis. A biopsy of the endobronchial lesions revealed non-necrotizing granulomatous inflammation, and a tissue culture identified Mycobacterium avium. An anti-human immunodeficiency virus antibody was negative. Finally, anti-interferon-gamma (IFN- $\gamma$ ) autoantibodies were detected, and the patient was diagnosed with disseminated nontuberculous mycobacterium infection with anti-IFN- $\gamma$ autoantibodies. Antimycobacterial therapy was effective, and radiographic findings, including the endobronchial lesions, were resolved.
\end{abstract}

Key words: disseminated nontuberculous mycobacterium infection, endobronchial lesion, anti-interferongamma autoantibodies, Mycobacterium avium

(Intern Med Advance Publication)

(DOI: 10.2169/internalmedicine.6693-20)

\section{Introduction}

Disseminated nontuberculous mycobacterium (NTM) infection usually occurs in immunocompromised individuals with impaired cell-mediated immunity, as seen in human immunodeficiency virus (HIV) infection, malignancy, and immunosuppressive therapy; however, it is rarely but occasionally found in patients with adult-onset immunodeficiency caused by anti-interferon-gamma (IFN- $\gamma$ ) autoantibodies $(1,2)$. Several studies of patients with disseminated NTM infections associated with anti-IFN- $\gamma$ autoantibodies have indicated that Mycobacterium avium complex (MAC) and M. abscessus are the most commonly identified mycobacteria, with the most commonly involved organs being the lymph nodes, bones, and lungs, while the bronchi are less frequently involved (3-7).

Endobronchial lesions from NTM are uncommon, regardless of the host's immune status (8-18). These lesions typically present as polypoid or ulcerative lesions and can lead to endobronchial obstruction $(8-12,16)$. There have been only a few reports of endobronchial lesions due to NTM infections in non-HIV adult patients, including cases with disseminated NTM infections associated with anti-IFN- $\gamma$ autoantibodies.

We herein report a case of disseminated $M$. avium infection with anti-IFN- $\gamma$ autoantibodies, for which the progression of the endobronchial polypoid lesions was confirmed by bronchoscopy over a short period.

${ }^{1}$ Department of Pulmonary Medicine, Seirei Hamamatsu General Hospital, Japan and ${ }^{2}$ Department of Respiratory Medicine, Faculty of Life Sciences, Kumamoto University, Japan

Received: November 9, 2020; Accepted: February 18, 2021; Advance Publication by J-STAGE: April 26, 2021

Correspondence to Dr. Masato Kono, masato.k@sis.seirei.or.jp 

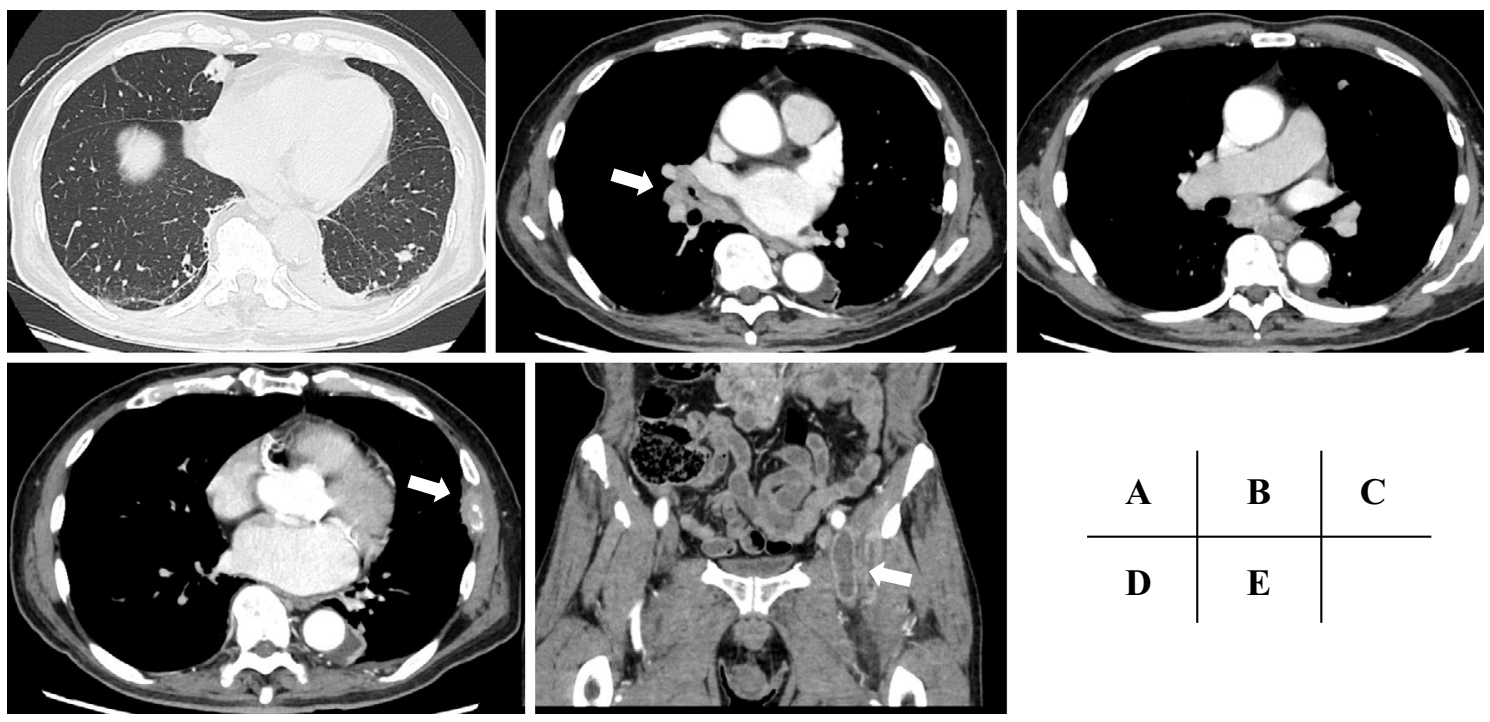

\begin{tabular}{c|c|c}
$\mathbf{A}$ & $\mathbf{B}$ & $\mathbf{C}$ \\
\hline $\mathbf{D}$ & $\mathbf{E}$ &
\end{tabular}

Figure 1. Chest computed tomography (CT) on admission showed multiple lung nodules (A), narrowing of the right bronchus intermedius (arrow) with hilar and mediastinal lymphadenopathy (B, C), an osteolytic lesion on the left 7th rib (arrow) (D), and a left iliopsoas muscle lesion (arrow) (E).

\section{Case Report}

A 78-year-old Japanese man was admitted to our hospital, presenting with a fever and left chest pain for the past 2 weeks. He was a never smoker and had a medical history of cervical spondylosis and hypertension. He had worked in the sales business, and there was no occupational or environmental exposure.

On a physical examination, there was slight swelling and tenderness over the left 7 th rib, and he had lost $3 \mathrm{~kg}$ within 2 months prior to admission. There was no wheezing or stridor on auscultation. Chest computed tomography (CT) revealed multiple lung nodules, narrowing of the right bronchus intermedius with hilar and mediastinal lymphadenopathy, and an osteolytic lesion on the left 7th rib (Fig. 1A-D). In addition, abdominal CT showed a low-density area in the left iliopsoas muscle. Laboratory data showed an elevated white blood cell count, $15,700 / \mu \mathrm{L}$; lactate dehydrogenase, $254 \mathrm{U} / \mathrm{L}$; alkaline phosphatase, $415 \mathrm{U} / \mathrm{L}$; and C-reactive protein, $8.3 \mathrm{mg} / \mathrm{dL}$. Soluble interluekin-2 receptor was high, at $2,990 \mathrm{U} / \mathrm{mL}$ (normal range: $145-519 \mathrm{U} / \mathrm{mL}$ ), but other tumor markers, including carcinoembryonic antigen, cytokeratin-19 fragments, and pro-gastrin-releasing peptide, were negative. An anti-glycopeptidolipid core $\operatorname{IgA}$ antibody assay kit for diagnosing MAC was positive at $1.54 \mathrm{U} / \mathrm{mL}$ (normal range: $<0.7 \mathrm{U} / \mathrm{mL}$ ). Anti-HIV antibody testing was negative. Empirical antibiotic therapy of meropenem $3 \mathrm{~g} /$ day was started but was ineffective.

Considering the possibility of malignant pulmonary disease or disseminated infection, endobronchial ultrasoundguided transbronchial needle aspiration (EBUS-TBNA) and needle biopsies of the osteolytic and the left iliopsoas lesions were performed. However, none of the samples yielded significant pathology or remarkable polymerase chain reaction (PCR) or culture findings. Since the bronchoscopic findings at the time of EBUS-TBNA demonstrated redness of the surface of the medial side of the right main bronchus and bronchial stricture at the right bronchus intermedius (Fig. 2A, B), bronchoscopy was repeated on day 7 after EBUS-TBNA for a transbronchial lung biopsy (TBB). Surprisingly, these endobronchial lesions had worsened in that short time without respiratory symptoms and showed multiple small polypoid lesions at the right main bronchus as well as progression of the stenosis at the right bronchus intermedius (Fig. 2C, D). The progression of endobronchial lesions was different from the TBNA biopsy site. A histological examination of the TBB samples from the right bronchus intermedius showed non-necrotizing granulomatous inflammation with epithelioid histiocytes (Fig. 3A). In addition, a mediastinal lymph node biopsy was performed via mediastinoscopy, and specimens were found to contain granulomatous inflammation (Fig. 3B). On a microbiological examination, $M$. avium was detected in the culture from the left pleural effusion fluid-findings that were increased on day 11 after admission-as well as in the endobronchial lesion biopsy specimens amplified via PCR.

Based on these results, this patient was suspected of having disseminated NTM disease. IFN- $\gamma$-releasing assays by the QuantiFERON ${ }^{\circledR}$-TB Gold In-tube (QFT-GIT) were indeterminate due to an undetectable IFN- $\gamma$ level in the mitogen tube, suggesting the presence of anti-IFN- $\gamma$ neutralizing autoantibodies. The neutralizing capacity of IFN- $\gamma$ and the relative concentration of anti-IFN- $\gamma$ autoantibodies were analyzed using previously reported methods $(6,19)$, and a hightiter of anti-IFN- $\gamma$ autoantibodies (427.8 E.U., control: 26.4 E.U.) with a biological neutralizing capacity (STAT 1 phosphorylation index: 3.8, control: 165.8) was detected. Ultimately, this patient was diagnosed with disseminated $M$. avium infection associated with anti-IFN- $\gamma$ autoantibodies. 

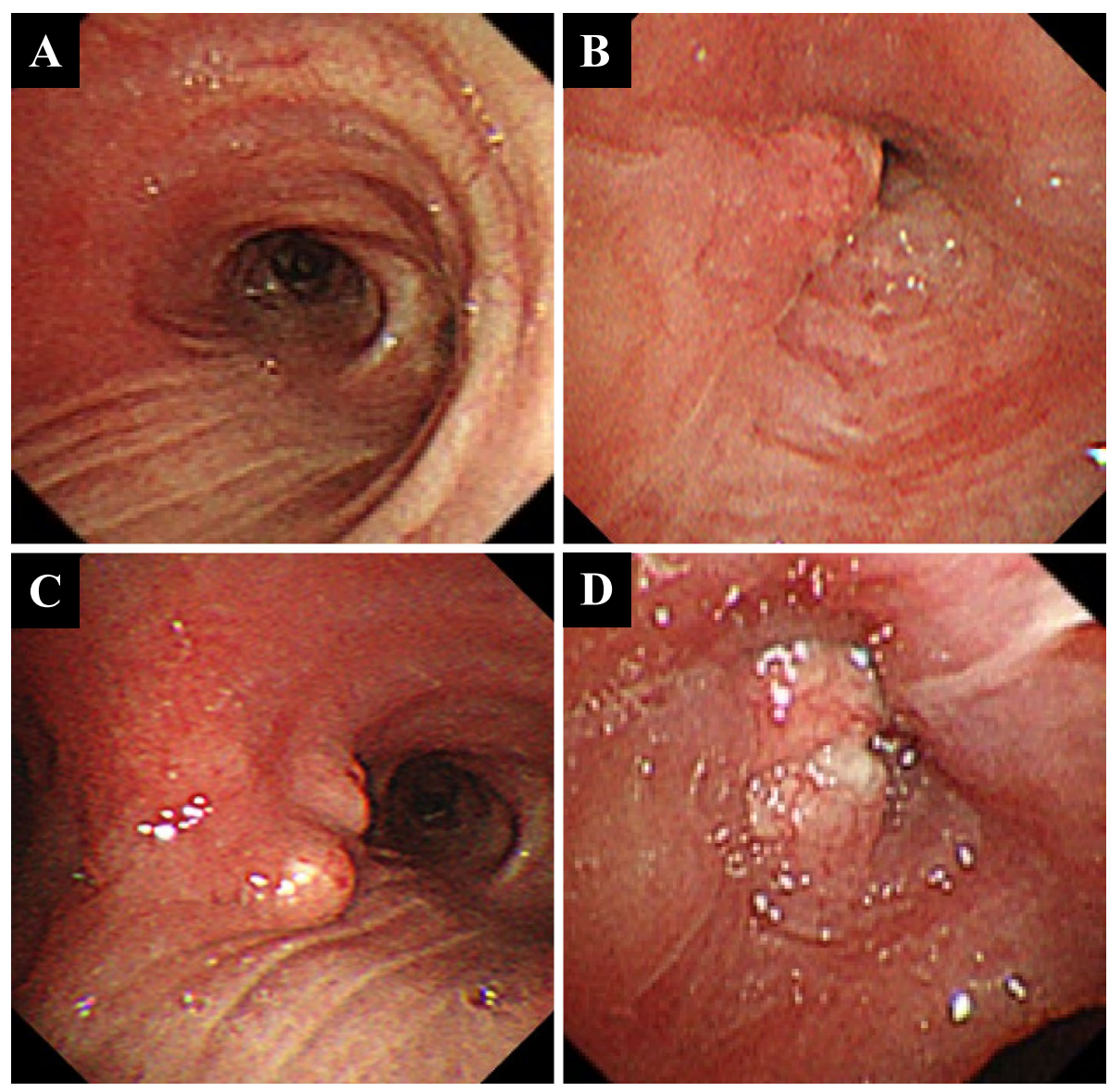

Figure 2. Bronchoscopic findings showed redness on the surface at the medial side of the right main bronchus (A) and bronchial stricture at the right bronchus intermedius (B). After seven days, these endobronchial lesions showed multiple small polypoid lesions at the right main bronchus $(\mathrm{C})$ and the progression of the stenosis at the right bronchus intermedius (D).
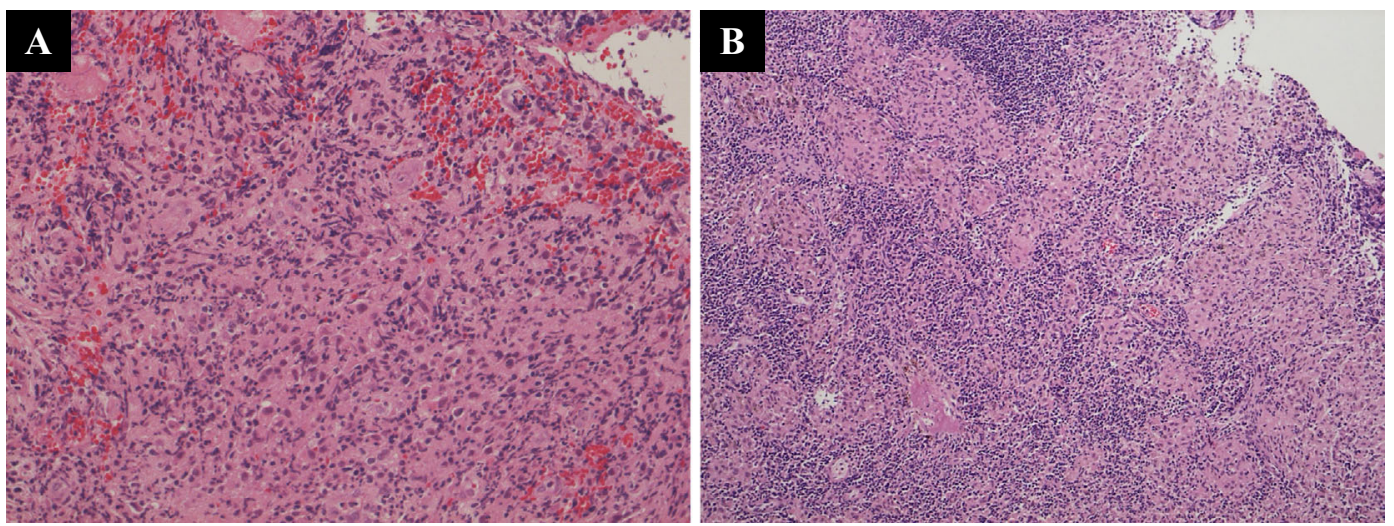

Figure 3. Histological findings from Hematoxylin and Eosin staining indicated non-necrotizing granulomatous inflammation with epithelioid histiocytes in the endobronchial lesion $(A: \times 300)$ and in the mediastinal lymph node $(\mathrm{B}: \times 200)$.

Antimycobacterial therapy was given on day 16 after admission, consisting of rifampicin (RFP, $450 \mathrm{mg} /$ day), ethambutol (EB, $750 \mathrm{mg} /$ day), clarithromycin (CAM, $400 \mathrm{mg}$ / day), and streptomycin (SM, $750 \mathrm{mg} / 3$ times a week), and the patient's fever resolved within a week. The patient's overall condition and systemic inflammation gradually improved, and he was discharged 40 days after admission. Fol- lowing initial antimycobacterial therapy for two months, the combination treatment of RFP, EB and CAM was continued. The radiographic findings, including narrowing of the right bronchus intermedius with hilar and mediastinal lymphadenopathy, were resolved three months after discharge. 
Table. Case Reports of Endobronchial NTM Infections in Non-HIV Adult Patients.

\begin{tabular}{|c|c|c|c|c|c|c|}
\hline $\begin{array}{l}\text { Author } \\
\text { (Year) }\end{array}$ & $\begin{array}{l}\text { Age/ } \\
\text { Sex }\end{array}$ & NTM species & $\begin{array}{l}\text { Anti-IFN- } \gamma \\
\text { antibodies }\end{array}$ & $\begin{array}{l}\text { Endobronchial } \\
\text { findings }\end{array}$ & $\begin{array}{l}\text { Pathological findings of } \\
\text { endobronchial lesion }\end{array}$ & Ref. \\
\hline $\begin{array}{l}\text { Connolly et al. } \\
\text { (1993) }\end{array}$ & $52 / \mathrm{F}$ & M. kansasii & N/A & Polypoid lesion & Granuloma formation & 8 \\
\hline $\begin{array}{l}\text { Shih et al. } \\
\text { (1997) }\end{array}$ & $34 / \mathrm{F}$ & $\begin{array}{c}\text { Disseminated } \\
\text { M. avium-intracellulare }\end{array}$ & N/A & Polypoid lesions & $\begin{array}{l}\text { Granulomatous inflammation } \\
\text { with necrotic debris }\end{array}$ & 9 \\
\hline $\begin{array}{l}\text { Asano et al. } \\
(2002)\end{array}$ & $45 / \mathrm{F}$ & $\begin{array}{l}\text { Disseminated } \\
\text { M. intracellulare }\end{array}$ & N/A & Polypoid lesions & Inflammatory infiltration & 10 \\
\hline $\begin{array}{l}\text { Fukuoka et al. } \\
(2003)\end{array}$ & $57 / \mathrm{M}$ & M. avium & N/A & Polypoid lesion & Granulomatous inflammation & 11 \\
\hline $\begin{array}{l}\text { Manali et al. } \\
(2005)\end{array}$ & $58 / \mathrm{M}$ & M. kansasii & N/A & Ulcerated lesion & $\begin{array}{l}\text { Non-necrotizing } \\
\text { granulomatous inflammation }\end{array}$ & 12 \\
\hline $\begin{array}{l}\text { Tanaka et al. } \\
(2013)\end{array}$ & $64 / \mathrm{F}$ & $\begin{array}{l}\text { Disseminated } \\
\text { M. intracellulare }\end{array}$ & Positive & $\begin{array}{l}\text { Multiple hemispherical } \\
\text { nodules }\end{array}$ & $\begin{array}{l}\text { Nonspecific granulation tissue } \\
\text { without apparent granuloma }\end{array}$ & 13 \\
\hline $\begin{array}{l}\text { Kang et al. } \\
(2013)\end{array}$ & $59 / \mathrm{F}$ & M. avium & N/A & $\begin{array}{l}\text { Irregular mucosal } \\
\text { lesions }\end{array}$ & $\begin{array}{l}\text { Granulomatous inflammation } \\
\text { with necrosis }\end{array}$ & 14 \\
\hline $\begin{array}{l}\text { Park et al. } \\
\text { (2013) }\end{array}$ & $58 / \mathrm{F}$ & M. intracellulare & N/A & $\begin{array}{l}\text { Diffuse actively } \\
\text { caseating lesions }\end{array}$ & $\begin{array}{l}\text { Granulomatous inflammation } \\
\text { with caseating necrosis }\end{array}$ & 15 \\
\hline $\begin{array}{l}\text { Kim et al. } \\
(2015)\end{array}$ & $37 / \mathrm{M}$ & M. avium & N/A & Ulcerative lesions & $\begin{array}{l}\text { Granulomatous inflammation } \\
\text { with necrosis }\end{array}$ & 16 \\
\hline $\begin{array}{l}\text { Saeki et al. } \\
(2017)\end{array}$ & $40 / \mathrm{M}$ & M. abscessus & N/A & Polypoid lesions & $\begin{array}{l}\text { Necrotic tissue without } \\
\text { granulomas }\end{array}$ & 17 \\
\hline $\begin{array}{l}\text { Cohen et al. } \\
(2017)\end{array}$ & $66 / \mathrm{F}$ & M. avium & N/A & Fibrinous mass & $\begin{array}{l}\text { Necrotic granulation tissue, } \\
\text { ulcerated bronchial mucosa }\end{array}$ & 18 \\
\hline $\begin{array}{l}\text { The present } \\
\text { case }\end{array}$ & $78 / \mathrm{M}$ & $\begin{array}{l}\text { Disseminated } \\
\text { M. avium }\end{array}$ & Positive & Polypoid lesions & $\begin{array}{l}\text { Non-necrotizing } \\
\text { granulomatous inflammation }\end{array}$ & N/A \\
\hline
\end{tabular}

NTM: nontuberculous mycobacterium, HIV: human immunodeficiency virus, IFN- $\gamma$ : interferon-gamma, F: female, M: male, M.: mycobacterium, N/A: not available, Ref.: Reference

\section{Discussion}

In the present report, we described a case of disseminated $M$. avium infection with anti-IFN- $\gamma$ autoantibodies. The disseminated lesions involved the lung, mediastinal lymph nodes, bone, muscle, and bronchus. Endobronchial lesions resulting from NTM infection are very uncommon, particularly in patients who are not immunocompromised. Interestingly, this patient was confirmed by bronchoscopy to have rapidly progressing endobronchial polypoid lesions, which progressed within a week. The biopsy of the endobronchial lesions revealed non-necrotizing granulomatous inflammation, and tissue culture identified $M$. avium as the etiology of the systemic infection. In addition, anti-IFN- $\gamma$ autoantibodies were ultimately found to be present. We believe that this case is extremely rare and provides valuable information that will aid in our understanding of the progression of endobronchial lesions resulting from NTM infections.

Disseminated NTM infections associated with anti-IFN- $\gamma$ autoantibodies have been previously described in immunocompetent adults (2-7). Anti-IFN- $\gamma$ autoantibodies have shown a neutralizing capacity against IFN- $\gamma$ and blocked the IFN- $\gamma$-interleukin-12 pathway, leading to the impairment of cellular immunity against mycobacterial pathogens (3-6). QFT-GIT assays may be used to screen for the presence of anti-IFN- $\gamma$ autoantibodies, due to undetectable or extremely low IFN- $\gamma$ level in the mitogen tube (20). In the present case, an indeterminate QFT-GIT result was useful for making the early diagnosis of disseminated NTM infection with anti-IFN- $\gamma$ autoantibodies. Several studies have demonstrated that MAC and M. abscessus were the predominant pathogens in patients with disseminated NTM infections with anti-IFN- $\gamma$ autoantibodies. The most common site of involvement was shown to be the lymph nodes, followed by the lungs, bones, joints, and less frequently, the bronchi (3-7). Hase et al. (4) reported that the frequency of endobronchial lesions in 111 NTM patients with anti-IFN- $\gamma$ autoantibodies was $6 \%$ and that patients with MAC infections had a higher incidence of endobronchial lesions than those with rapidly growing mycobacteria.

Endobronchial lesions caused by NTM infections are uncommon in both immunocompetent and immunocompromised hosts. To date, only 11 cases of endobronchial lesions from NTM infections in adult non-HIV patients have been reported, as summarized in Table (8-18). Among these cases, MAC was the most common mycobacterium found (9-11, 13-16, 18), followed by $M$. kansasii $(8,12)$ and $M$. abscessus (17). Four of the cases, including the present patient, were diagnosed with disseminated MAC infections $(9,10,13)$, and only two were positive for anti-IFN- $\gamma$ autoantibodies (13). The endobronchial findings of these patients indicated polypoid or ulcerated lesions, similar to those seen with endobronchial tuberculosis $(21,22)$, and in some cases, polypoid masses caused endobronchial obstruction $(8-12,16)$. In addition, the histological findings of these 
endobronchial lesions revealed granulomatous inflammation in most cases, for which tissue cultures identified NTM. In the present case, we performed biopsies of multiple sites, including the bone, mediastinal lymph nodes, and endobronchial lesions, but MAC was only identified in tissue cultures from the endobronchial lesions and pleural effusion specimens.

The mechanism underlying endobronchial NTM remains unclear, but it may be similar to the pathogenesis of endobronchial tuberculosis. Shih et al. (9) suggested that endobronchial lesions from NTM infections might be the result of erosion of mediastinal lymph nodes. In particular, in all four patients, including the present patient, who were previously reported in Table as having endobronchial lesions from disseminated MAC infections, there was evidence of marked hilar and / or mediastinal lymphadenopathy $(9,10,13)$. In addition, in the present case, we confirmed the rapid progression of endobronchial lesions on the adjacent-central side of the bronchus via bronchoscopy. These findings suggest that the endobronchial lesions caused by disseminated NTM infections may occur as local lymphatic infiltrations rather than as hematogenous dissemination. Furthermore, although the mechanism by which endobronchial lesions worsen rapidly is unclear, the present case suggests that the progression of endotracheal lesion can occur rapidly without respiratory symptoms in disseminated NTM infection associated with anti-IFN- $\gamma$ autoantibodies.

No standard therapy has been established for managing non-HIV patients with disseminated NTM infections. Despite treatment with species-specific antimycobacterial therapy, these patients are associated with persistent NTM infections, recurrence, or re-infection, and require long-term therapy (4-7). Endobronchial lesions due to NTM infections need to be aggressively treated, since these lesions can lead to endobronchial narrowing or obstruction as a result of disease progression $(8-12,16)$. Previous reports have described the resolution of the endobronchial lesions from NTM infections using multidrug antimycobacterial therapy $(9,10,15)$, and laser resection and/or balloon bronchoplasty were effective in relieving the airway obstruction in some cases $(9,12)$. In the present case, fortunately, the antimycobacterial therapy was effective, and the subsequent radiographic findings, including endobronchial stenosis and lesions, were almost completely improved, although the patient requires careful long-term follow-up.

In conclusion, we encountered a case of disseminated $M$. avium infection associated with anti-IFN- $\gamma$ autoantibodies with the rapid progression of endobronchial polypoid lesions confirmed via bronchoscopy. The evaluation of endobronchial lesions may be important for correctly diagnosing an infection and preventing an unfavorable outcome in patients with suspected anti-IFN- $\gamma$ autoantibodies-associated NTM infections.

The authors state that they have no Conflict of Interest (COI).

\section{References}

1. Henkle E, Winthrop KL. Nontuberculous mycobacteria infections in immunosuppressed hosts. Clin Chest Med 36: 91-99, 2015.

2. Browne SK, Burbelo PD, Chetchotisakd P, et al. Adult-onset immunodeficiency in Thailand and Taiwan. N Engl J Med 367: 725734, 2012.

3. Kampitak T, Suwanpimolkul G, Browne S, Suankratay C. Antiinterferon $-\gamma$ autoantibody and opportunistic infections: case series and review of the literature. Infection 39: 65-71, 2011.

4. Hase I, Morimoto K, Sakagami T, Ishii Y, van Ingen J. Patient ethnicity and causative species determine the manifestations of antiinterferon-gamma autoantibody-associated nontuberculous mycobacterial disease: a review. Diagn Microbiol Infect Dis 88: 308315, 2017.

5. Chi CY, Lin CH, Ho MW, et al. Clinical manifestations, course, and outcome of patients with neutralizing anti-interferon- $\gamma$ autoantibodies and disseminated nontuberculous mycobacterial infections. Medicine (Baltimore) 95: e3927, 2016.

6. Aoki A, Sakagami T, Yoshizawa K, et al. Clinical Significance of Interferon- $\gamma$ Neutralizing Autoantibodies Against Disseminated Nontuberculous Mycobacterial Disease. Clin Infect Dis 66: 12391245, 2018.

7. Hong GH, Ortega-Villa AM, Hunsberger S, et al. Natural History and Evolution of Anti-Interferon- $\gamma$ Autoantibody-Associated Immunodeficiency Syndrome in Thailand and the United States. Clin Infect Dis 71: 53-62, 2020.

8. Connolly MG Jr, Baughman Rp, Dohn MN. Mycobacterium kansasii presenting as an endobronchial lesion. Am Rev Respir Dis 148: 1405-1407, 1993.

9. Shih JY, Wang HC, Chiang P, Yang PC, Luh KT. Endobronchial lesions in a non-AIDS patient with disseminated Mycobacterium avium-intracellulare infection. Eur Respir J 10: 497-499, 1997.

10. Asano T, Itoh G, Itoh M. Disseminated Mycobacterium intracellulare Infection in an HIV-negative, nonimmunosuppressed patient with multiple endobronchial polyps. Respiration 69: 175-177, 2002.

11. Fukuoka K, Nakano Y, Nakajima A, Hontsu S, Kimura H. Endobronchial lesions involved in Mycobacterium avium infection. Respir Med 97: 1261-1264, 2003.

12. Manali ED, Tomford WJ, Liao DW, Farver C, Mehta AC. Mycobacterium kansasii endobronchial ulcer in a nonimmunocompromised patient. Respiration 72: 305-308, 2005.

13. Tanaka H, Yamaguchi E, Fukuda T, Ohbayashi Y, Sato M, Yokoi T. A case of disseminated nontuberculous mycobacteriosis and cerebellar toxoplasmosis with autoantibody to interferon- $\gamma$. Sarcoidosis Vasc Diffuse Lung Dis 30: 312-316, 2013.

14. Kang SH, Mun SK, Lee MJ, et al. Endobronchial Mycobacterium avium Infection in an Immunocompetent Patient. Infect Chemother 45: 99-104, 2013.

15. Park JS, Jung ES, Choi W, et al. Mycobacterium intracellulare Pulmonary Disease with Endobronchial Caseation in a Patient Treated with Methotrexate. Tuberc Respir Dis (Seoul) 75: 28-31, 2013.

16. Kim HI, Kim JW, Kim JY, et al. Isolated Endobronchial Mycobacterium avium Disease Associated with Lobar Atelectasis in an Immunocompetent Young Adult: A Case Report and Literature Review. Tuberc Respir Dis (Seoul) 78: 412-415, 2015.

17. Saeki K, Watanabe S, Waseda Y, Kasahara K. Endobronchial Lesions of Mycobacterium abscessus Infection in an Immunocompromised Patient. Am J Respir Crit Care Med 195: e37-e38, 2017.

18. Cohen L, Guarner J, Hunt WR. A novel presentation of Mycobacterium avium complex in a recipient of a lung transplant: a case report. J Med Case Rep 11: 240, 2017.

19. Shima K, Sakagami T, Tanabe Y, et al. Novel assay to detect increased level of neutralizing anti-interferon gamma autoantibodies 
in non-tuberculous mycobacterial patients. J Infect Chemother 20: 52-56, 2014.

20. Wu UI, Chuang YC, Sheng WH, et al. Use of QuantiFERON-TB Gold In-tube assay in screening for neutralizing anti-interferon- $\gamma$ autoantibodies in patients with disseminated nontuberculous mycobacterial infection. Clinical Microbiology and Infection 24: 159165, 2018.

21. Shim YS. Endobronchial tuberculosis. Respirology 1: 95-106,
1996.

22. Chung HS, Lee JH. Bronchoscopic assessment of the evolution of endobronchial tuberculosis. Chest 117: 385-392, 2000.

The Internal Medicine is an Open Access journal distributed under the Creative Commons Attribution-NonCommercial-NoDerivatives 4.0 International License. To view the details of this license, please visit (https://creativecommons.org/licenses/ by-nc-nd/4.0/).

(C) The Japanese Society of Internal Medicine Intern Med Advance Publication 